s Research Square

\title{
Prevalence of depressive symptoms and its predicted factors among medical students in University of Bisha, Saudi Arabia
}

Mohammad S. Al-Shahrani

University of Bisha

Muffarah H. Alharthi

University of Bisha

Mohannad S. Alamri

University of Bisha

Mutasim E Ibrahim ( $\square$ mutasimhadi8@hotmail.com )

University of Bisha https://orcid.org/0000-0002-1734-8439

\section{Research}

Keywords: depression, predicated factors, medical students, Saudi Arabia

Posted Date: March 9th, 2020

DOI: https://doi.org/10.21203/rs.3.rs-16461/v1

License: (c) (i) This work is licensed under a Creative Commons Attribution 4.0 International License. Read Full License 


\section{Abstract}

Background: Identification of the potential factors of depression among medical students is the first step towards academic excellence and future safe medical practice.

Methods: A cross-sectional study was conducted during a period from November 2019 to February 2020 at the University of Bisha, College of Medicine (UBCOM), Bisha province, Saudi Arabia. Medical students from year one to year six were involved. A self-administered questionnaire was used to collect data about socio-demographic and academic characteristics of students. The Arabic version of the PHQ-9 scale with a score of $\geq 10$ was used for diagnosis depressive. Logistic regression analysis was used to assess the prevalence and risk of depression.

Results: Of the 190 students enrolled, $26.8 \%$ had depressive symptoms, of which $45.1 \%$ were having moderate to severe symptoms. The highest proportion of depression was found among second-year students (43.8\%), followed by sixth-year students (41.2\%), whereas lowest proportion of depression reported among first-year students (8.9\%). Univariate regression revealed significant associations between depression and un-satisfaction of family income, loss of family members, having psychological illness, difficulties in personal relationships, regretted study medicine, failure in academic year, a lower grade than expected, conflict with tutors, lack of college facilities and heavy academic load. In multivariate analysis, loss of a family members ( $A O R=0.077 ; 95 \% \mathrm{Cl} 0.013-0.451)$, difficulties in personal relationships (AOR=2.371; 95\% $\mathrm{Cl} 1.009-5.575)$, regret study medicine ( $\mathrm{AOR}=3.764 ; 95 \% \mathrm{Cl} 1.657-8.550)$, failed in academic year ( $A O R=2.559 ; 95 \% \mathrm{Cl} 1.112-5.887)$ were independently associated with depression.

Conclusion: The study concluded that medical students at UBCOM also experience the existence of depressive symptoms associated with various risk indicators. Optimizing the educational and social environment coupled with infrastructure facilities at UBCOM might promote students' mental health and well-being.

\section{Introduction}

Depression is a common mental disorder expressed by loss of interest and pleasure, persistent sadness, decreased energy, inability to carry out daily activities and poor concentration[1,2]. This disorder can affect all health aspects of the individual, including physical condition, mental, academic performance and social life[3]. Globally, about 350 million individuals suffer from depression and almost $3.2 \%$ of them express having an episode of depression at least one time in their lives [4]. Medical students are seen under a noticeable degree of psychological morbidity ranging from stress, interpersonal problems and suicidal ideation to psychiatric disorders compared with other populations[1,5]. The potential effects of depression on medical students include impairment of functioning in classroom and patient care settings that would reflect negatively on the community health $[1,6]$.

The prevalence of depression among medical students has been well documented in worldwide studies[4,5,7]. In a systematic review across 47 countries demonstrated that $27.2 \%$ of medical students 
screened positive for depression[8]. However, the prevalence varies across different countries. In Saudi Arabia, the prevalence of depressive symptoms has been determined with high rates among medical students at several universities[2,9-12]. Despite the increasing number of medical schools in Saudi Arabia, such studies are not available in many medical schools.

Widely accepted that medical students at risk of depression due to frequent academic demands, poor learning environments, and inability to cope with stressful situations in clinical practice[1,13]. Also, many indicators of social life, physical health, history of psychological illness, and financial concerns make medical students more susceptible to depression[2,14]. Well known that early onset of depression keeps medical students at higher risk for problems such as substance abuse and suicidal behavior[15].

Therefore, medical students at extreme risk of depression need serious attention to identify and tackle the possible factors that impair their academic path and future professional career[1]. However, identification of depressive symptoms and their potential factors among medical students is the first step towards academic excellence and safe medical practice. The present study aimed to determine the prevalence of depression and its potential factors among medical students in the University of Bisha, Bisha province, southwest of Saudi Arabia.

\section{Methods}

\section{Study design and setting}

A cross-sectional study was conducted during a period from November 2019 to February 2020 at the University of Bisha, College of Medicine (UBCOM) in Bisha province, southwest of Saudi Arabia. Medical students at different academic levels from year one to year six were enrolled in the study.

The UBCOM is a new medical school in Saudi Arabia, which was established in 2014 to contribute to improving the health care status in the country. The educational program in UBCOM is an integrated curriculum that is utilizing problem-based learning strategies blended with various students centered activities. The medical curriculum in UBCOM is implemented from year two to six, whereas the first year is a preparatory phase[16].

\section{Procedures of sampling collection}

The data was collected using a self-administered questionnaire, which consisting of two forms: The first part of the questionnaire contains data about participants' demographic characteristics, academic information, medical history and socio-psychological status. These factors were obtained after an extensive review of the related literature and have been found to contribute to depression symptoms among medical students. The second part contains the Patient Health Questionaire-9 (PHQ-9) to evaluate the presence of depression among the participants. 
The participants fully completed the questionnaire forms during class time, where the full attendance expected. Cover letters that described the purpose of the survey was distributed with questionnaires in the presence of the researchers to clarify any queries or doubts. Participating in the study was anonymous and voluntary, with no influence on the progress of their educations. Students who absent during the survey or not registered for the current academic year were excluded from the study.

\section{Description of PHQ-9 instrument}

A translated Arabic version of the PHQ-9 scale was used for the study. This version has been previously tested its validity and reliability as a suitable tool for the detection of depressive symptoms in the Saudi Arabian context[17]. The PHQ-9 is self-administered instrument consists of nine items (from 1 to 9), each is based on a four-point Likert-type scale that scores for the presence of depression symptoms from zero to three as follow: "not at all", "several days", "more than half the days", and "nearly every day", respectively. Participants diagnosed with depression if their responses to the below depressive symptoms criteria were met and existing for the past two weeks. Therefore, major depressive was accounted for if the answer to item number 1 or 2 and four or more of the remaining PHQ-9 items recorded at least as "more than half the days". Based on these criteria, a PHQ -9 score of $\geq 10$ was used as a diagnostic cutoff point for depressive symptoms as previously recommended in the literature[17,18].

\section{Statistical analysis}

Data was entered and analyzed using the Statistical Package for Social Sciences (SPSS version 22) (Armonk, NY: IBM Corp.). A descriptive analysis was used to summarize data in terms of distributions, frequencies and proportions. Chai-square test was used to compare the proportion of depressive symptoms between students at different academic levels. Univariate logistic regression was performed to identify the predictive factors of depression and presented as crude odds ratios (COR) with $95 \%$ confidence intervals $(\mathrm{Cl})$. Then all independent variables with $\mathrm{p}<0.05$ values were retained for multivariate analysis. Multivariate logistic regression was used to identify independent associations with depressive symptoms and presented as adjusted odds ratios (AOR) with $95 \% \mathrm{Cl}$. The AOR with $95 \% \mathrm{Cl}$ and a p-value of 0.05 were used to determine the final model.

\section{Results}

\section{Socio-demographic characteristics of participants}

Of the 201 medical students registered in UBCOM, 190 were participated in the study, giving an estimated response rate of $94.5 \%$. Of these participants, $45(23.7 \%)$ were from year one, $32(16.8 \%)$ from year two, $41(21.6 \%)$ from year three, $25(13.2 \%)$ from year four, 30 (15.8\%) from year five and $17(8.9 \%)$ from year six. The age of participants ranged from 18 to 25 years, with a mean of $21.1 \pm 2.0$. 
Of the total number of students $(n=190)$ enrolled, $118(62.1 \%)$ were from Bisha province and the majority $(75.3 \%)$ were living with their families or friends. Most of the participants were satisfied with their family income (86.3\%) and reported a stable parental relationship (88.9\%). The minority of students were recorded being/or his family member with a psychological illness (11.6\%), and loss of family members during the last month (12.1\%). Students perceived limited time for social activities recorded as $77.4 \%$, whereas $23.7 \%$ of them reported difficulties in personal relationships and $24.2 \%$ were using stimulant (tobacco, khat, alcohol and drug addiction). With regards to educational aspects, $25.8 \%$ of the students were regretted to study medicine, $30.0 \%$ failed in an academic year, $69.5 \%$ suggested having lower grade than expected, $80.5 \%$ reported lack of the college facilities, $65.5 \%$ complained from the heavy academic load and $14.2 \%$ having a conflict with tutors. The detailed demographic characteristics of the participants are shown in Table 1

\section{Prevalence of depression}

The prevalence of depressive symptoms using PHQ-9 (score $\geq 10$ ) was $26.8 \%$ (51/190). Of these cases, $45.1 \%(n=23)$ were having moderate to severe symptoms, $29.4 \%(n=15)$ with severe symptoms, and $25.5 \%(n=13)$ with moderate symptoms (Figure 1). The highest proportion of depression was found among the second-year students (43.8\%), followed by the sixth year students (41.2\%) and the third-year students (34.1\%). However, the lowest proportion of depression was reported among first-year students (8.9\%) (Table 1 and Figure 2).

\section{Factors associated with depressive symptoms}

The results of univariate and multivariate analysis of the risk factors associated with depression are shown in Table 1 and 2. In univariate analysis, the risk of depressive symptoms was found to be significantly increased among students with the presence of the following factors: un-satisfaction of family income $(\mathrm{COR}=2.747 ; 95 \% \mathrm{Cl} 1.173-6.432)$, loss of their family members $(\mathrm{COR}=0.229 ; 95 \% \mathrm{Cl}$ $0.052-1.016)$, having or a family member with psychological illness (COR $=2.581 ; 95 \% \mathrm{Cl} 1.039-6.413)$, having difficulties in personal relationships ( $\mathrm{COR}=2.942 ; 95 \% \mathrm{Cl} 1.447-5.981)$, being regretted study medicine $(\mathrm{COR}=5.245 ; 95 \% \mathrm{Cl} 2.583-10.650$, being failed in academic year $(\mathrm{COR}=2.537 ; 95 \% \mathrm{Cl} 1.293-$ 4.975), received lower grade than expected $(\mathrm{COR}=3.020 ; 95 \% \mathrm{Cl} 1.316-6.928)$, having conflict with tutors (COR $=2.544 ; 95 \% \mathrm{Cl} 1.098-5.892)$, perceived lack of college facilities (COR $=2.751 ; 95 \% \mathrm{Cl}$ $1.008-7.508)$, felt heavy academic load ( $\mathrm{COR}=2.310 ; 95 \% \mathrm{Cl} 1.092-4.888)$ (Table 1). Based on the retention of the significant relationships for the multivariate analysis, the independent risk factors that predicted the depressive symptoms were loss of family members during last month $(\mathrm{AOR}=0.077 ; 95 \% \mathrm{Cl}$ 0.013-0.451), and difficulties in personal relationships ( $A O R=2.371 ; 95 \% \mathrm{Cl} 1.009-5.575)$, regret study medicine $(A O R=3.764 ; 95 \% \mathrm{Cl} 1.657-8.550)$, failed in academic year $(\mathrm{AOR}=2.559 ; 95 \% \mathrm{Cl} 1.112-5.887)$ (Table 2). 


\section{Discussion}

The present study determined the prevalence and predicted factors of depression among medical students at the UBCOM, Bisha province in the southern region of Saudi Arabia. The overall prevalence of depression among students was $26.8 \%$. This finding was higher than that reported among medical students at King Faisal University in the eastern region of Saudi Arabia (16.2\%)[12]. However, our result was lower than that reported among medical students in Albaha University in Albaha neighboring city (53.8\%)[13], in Umm Al-Qura University, Makkah Al-Mukaramah (34.5\%)[6], and in King Saud University, Riyadh capital (48.2\%)[19]. In neighboring countries, the prevalence of depression among medical students found to be 17.2\% in Oman [20], and $40 \%$ in Bahrain[21]. Moreover, recent studies from other countries revealed variable prevalence rates of depression ranging between $71 \%$ to $13.6 \%$ [4,22-25]. Such discrepancy in the level of depression could be attributed to the differences in socio-cultural and demographic structures of medical students or due to the variation of academic environments between medical schools. Other possibilities might be to the differences in sample size selected, types of tools for depression assessment and the cut off values used to estimate the rate of depression.

Comparing the level of depression by the academic year, the second-year students scored the highest depression rate. This result is consistent with previous studies using different assessment tools for depression[26]. For instance, high rates of depression have been determined by the PHQ-9 scale among the second-year medical students in Korea [27], and Malaysia[24]. These observations could be explained by that medical students could face a more complex curriculum in the second year. In fact, the first cycle of the medical curriculum in UBCOM starts from year two, where the students should understand the extensive basic knowledge of the human body and function in health and disease in this phase. Increasing the level of depression among students during the early stages of medical schools has been reported in several studies. Vankar et al. determined that the prevalence of self-identified depression was significantly higher in the first year and second years as compared to the third and fourth years[26]. In a longitudinal study, Roh et al. have suggested that depression rates increase during the first year and then reach the peak level during the second year, followed by a gradual decline during the later years of medical school[28]. A recent study in Saudi Arabia conducted among medical science students found the level of depression starts to escalate from the pre-professional year, reach the peak at the third professional year and then decreased in the final year of graduation[2].

Interestingly, our sixth-year students recorded the second-highest rate of depression. This might be due to the increasing demand for clinical training, along with new concerns and responsibilities of students during such academic levels. A recent study highlighted several stressful situations like using psychometric skills, applying clinical knowledge in real-life situations, trauma exposure, understanding the role and regulating of clinical settings during their clerkship[29]. Lin et al. argued that medical students, as novices in medical practice, experience greater physical demands resulting from their lack of efficiency or familiarity with the workload, leading to frustration in learning and reducing their compassion satisfaction[29]. Therefore, understanding of clinical learning process along with essential 
supervision by clinicians in various disciplines might lead to a stress-free learning environment for our students in patient care and hospital setting.

In the present study, we identified a combination of predicted factors associated with depression. In univariate analysis, students who perceived insufficient family income were about three times tend to get depressive symptoms than other students. This association has been reported by many authors $[19,28]$. However, our result failed to determine a significant association between depression and family income at the multivariate level when adjusting other confounding factors. A previous study in Saudi Arabia suggested an insignificant association between the financial income and likelihood of depression due to the subjectivity of the income estimation[19].

The present study indicated that the loss of family members and having psychological illnesses were possible risk factors for depression. However, at the multivariate level, the loss of a family member remained a significant indicator of depression. Likewise, studies in Saudi Arabia linked the presence of depressive symptoms with physiological illness[2,13], and the loss of a family member[2]. Furthermore, inconsistent with a previous study in Saudi Arabia[30], we did not find significant associations between depression and parents' educational levels.

In the present study, medical students who had difficulties in personal relationships were about two and a half times more tendencies to develop depression. This might be attributed to the heavy academic requirements of studying medicine, which leave no time for building good personal relationships with friends or society. The other possible reason is that many students at UBCOM who are leaving their base home could fail to adapt to the new society and environments. Previous studies related increasing the rate of mental disorders to the feeling of isolation from family and community[15,25]. The high rate of depression observed among our students those having difficulties in personal relationships highlighted the importance of social support from peers, faculty members, activating of students' academic counseling. However, focus group discussions with our students might be an essential approach to figure out their essential needs.

Several studies have evaluated the contribution of depression-related factors to the academic status of the medical institution[2,19]. In our findings, students perceived a lack of college facilities were about three times depressed than other students. Likewise, a study conducted at King Saud University in Riyadh capital found that medical students with negative perceptions about the educational environment were having a high rate of depressive symptoms[19]. Additionally, since UBCOM is a newly established medical school, it still has limitations in infrastructure and educational facilities. Therefore, university administration could play a crucial role in supporting the learning environment overall the medical school.

Evidence indicated that students at medical school could impose significant psychological stress due to substantial academic requirements[2,22]. In the present study, the regret of studying medicine is the persistent and strong factor for causing depression. However, having a regret feeling of studying medicine found to be a correlate of depression in many studies[4,30]. This can be explained by that many students might found curriculum difficulties and demanding nature of studying medical school than they 
expected. However, our study found a significant association between depression and heavy academic load. Another possible factor could be a lack of interest and motivation of students after joining the medical school. Research showed that many students select a medicine career because of family pressure rather than their self-interest[31]. Therefore, understanding the factors influencing students to choose medicine as a career are need to be investigated. Furthermore, implementing appropriate quality assurance procedures along with students' perception are recommended to evaluate medical curriculum contents, teaching and learning strategies.

Regarding the academic performance, the proportion of depression was significantly increased among students who perceived their academic grade was lower than expected. Similar findings have been observed in Korea[27], and India[32]. Yoon et al. found that academic achievement was significantly related to the mean PHQ-9 score, and the prevalence of depression was significantly higher in poorperceived academic achievers than in excellent or fair achievers[27]. In contrary, another study assumed that higher academic achievers might be under massive stress due to the competitive nature of the medical school[32]. The present study also found a strong association between academic failure and depression, confirming previous findings[33]. Research evidence indicated that depressive symptoms among medical and non-medical students were linked to frequent courses failure and lower curricular average grade[34]. Noticeably, our medical students who failed at least in one academic year or a course were about three times depressed than those who are not failed during their study. Such a situation urge for adopting a mentorship program combined with academic counseling and psychiatric services to guide students toward academic excellence.

\section{Limitation}

The study provides several limitations that need to be considered. Firstly, this was a cross-sectional design that used a self-assessment measure without any confirmation from clinical physicians. Secondly, depressive symptoms were identified based on a PHQ- $9 \geq 10$ score; therefore, the association between risk factors and the severity of depression was not identified more clearly. Thirdly, the study did not include students who dropped or absent during the survey, which might affect the rate of depression among our medical students. Finally, the study included only male students; in fact, the medical program for the females at the UBCOM had not yet started.

\section{Conclusions}

The study concluded that medical students at UBCOM also experience the existence of depressive symptoms. Various risk indicators of depression dealt with students' social life and academic functioning identified in this study. Such situations study may require more careful attention from medical schools and university administration for prevention and early detection of depression. In this regard, consider optimizing the learning environment in their educational, social, and psychological contexts, coupled with infrastructure facilities at UBCOM might promote students' mental health and well-being. 


\section{Declarations}

\section{List of abbreviations}

AOR: Adjusted Odd Ratio; Cl: Confidence Interval; COR: Crude Odd Ratio; PHQ-9: Patient Health Questionaire-9; SPSS: Statistical Package for Social Sciences; UBCOM: University of Bisha, College of Medicine.

\section{Acknowledgment:}

The authors would like to acknowledge the contribution of the students at the University of Bisha, College of Medicine who participated in this study.

\section{Contributors:}

$M A^{1}, M H A, M S A^{2}$, MEl conceived the idea of the study and developed the protocol. MSA ${ }^{1}, M^{2} A^{2}$ and MEI designed and conducted the study. $M^{2} A^{2}$ and MEl collected the data. MSA ${ }^{1}$ and MEl analysed and interpreted the data and wrote initial draft. MSA ${ }^{1}, \mathrm{MHA} \mathrm{MSA}^{2}, \mathrm{MEl}$ reviewed the literature. MHA and MEI revised the study for important intellectual contents. All authors have investigated the final draft and are accountable for the content and similarity index of the manuscript.

\section{Funding:}

The study received no specific grant.

\section{Availability of data and materials:}

The datasets during and/or analysed during the current study are available from the corresponding author on reasonable request.

\section{Competing interests:}

None declared

\section{Ethics approval and consent to participate:}


Ethical approval was obtained from the Research Ethics Local Committee at the UBCOM (Ref No.: UBCOM/H-06-BH-087(03/13)). Oral informed consent obtained from the participants prior to the start of the interview.

\section{Consent for publication}

Not applicable

\section{References}

1. Ngasa SN, Sama C, Dzekem BS, Nforchu KN, Tindong M, Aroke D, et al. Prevalence and factors associated with depression among medical students in Cameroon: a cross-sectional study. BMC Psychiatry. BMC Psychiatry; 2017;17:216.

2. Hamasha AAH, Kareem YM, Alghamdi MS, Algarni MS, Alahedib KS, Alharbi FA. Risk indicators of depression among medical, dental, nursing, pharmacology, and other medical science students in Saudi Arabia. Int Rev Psychiatry. Taylor \& Francis; 2019;0:1-7.

3. Aldabal B, Koura M, Alsowielem L. Magnitude of depression problem among primary care consumers in Saudi Arabia. Int J Med Sci Public Heal. 2015;4:205.

4. Njim T, Mbanga CM, Tindong M, Fonkou S, Makebe $H$, Toukam L, et al. Burnout as a correlate of depression among medical students in Cameroon: a cross-sectional study. BMJ Open. 2019;9:e027709.

5. Iqbal S, Gupta S, Venkatarao E. stress, anxiety \& depression among medical undergraduate students \& their socio-demographic correlates. Indian J Med Res. 2015;141:354-7.

6. Alkot MM, Alnewirah AY, Bagasi AT, Alshehri AA, Bawazeer NA. Depression among Medical versus Non-Medical Students in Umm Al-Qura University, Makkah Al-Mukaramah, Saudi Arabia. Am J Psychiatry Neurosci. 2017;5:1-5.

7. Mayer FB, Santos IS, Silveira PSP, Helena M, Lopes I, Regina A, et al. Factors associated to depression and anxiety in medical students: a multicenter study. BMC Med Educ. BMC Medical Education; 2016;16:282.

8. Peluso MJ, Guille C, Sen S, Mata DA. Prevalence of Depression, Depressive Symptoms, and Suicidal Ideation Among Medical Students: A Systematic Review and Meta-Analysis. JAMA. 2017;316:221436.

9. Kulsoom B, Afsar NA. Stress, anxiety, and depression among medical students in a multiethnic setting. Neuropsychiatr Dis Treat. 2015;11:1713-22.

10. SN Bazmi Inam. Anxiety and Depression among Students of a Medical College in Saudi Arabia SN. Bazmi Inam,. Int J Heal Sci Qassim Univ. 2007;1:295-300.

11. Hakami RM. Prevalence of Psychological Distress Among Undergraduate Students at Jazan University: A Cross - Sectional Study. Saudi J Med Med Sci. 2018;6:82-8. 
12. El-Gilany AH, Amr M HS. Perceived stress among male medical students in Egypt and Saudi Arabia: effect of sociodemographic factors. Ann Saudi Med. 2008;28:442-8.

13. Albajjar MA, Bakarman MA. Prevalence and correlates of depression among male medical students and interns in Albaha University, Saudi Arabia. J Fam Med Prim Care. 2019;8:1889-94.

14. Bedaso A, Kediro G, Yeneabat T. Factors associated with depression among prisoners in southern Ethiopia : a cross - sectional study. BMC Res Notes. BioMed Central; 2018;11:637.

15. Kumar GS, Jain A, Hegde S. Prevalence of depression and its associated factors using Beck Depression Inventory among students of a medical college in Karnataka. Indian J Psychiatry. 2020;54:223-6.

16. Ibrahim M, Al-Shahrani A. Implementing of a problem-based learning strategy in a Saudi medical school: requisites and challenges. Int J Med Educ. 2018;9:83-5.

17. Alhadi AN, Alateeq DA, Sharif E Al, Bawazeer HM, Alanazi H, Alshomrani AT, et al. An arabic translation, reliability, and validation of Patient Health Questionnaire in a Saudi sample. Ann Gen Psychiatry. BioMed Central; 2017;16:32.

18. Inoue T, Tanaka T, Nakagawa S, Nakato Y, Kameyama R, Boku S, et al. Utility and limitations of PHQ9 in a clinic specializing in psychiatric care. BMC Psychiatry. 2012;12:73.

19. Al-Faris EA, Irfan F, Van der Vleuten CPM, Naeem N, Alsalem A, Alamiri N, et al. The prevalence and correlates of depressive symptoms from an Arabian setting: A wake up call. Med Teach. 2012;34 suppl 1:S32-6.

20. Al-kindi R, Al-shafaee M, Al-maniri A. Prevalence of Depressive Symptoms among University Students in Oman. Oman Med J. 2011;26:235-9.

21. Mahroon ZA, Borgan SM, Kamel C, Maddison W, Royston M, Donnellan C. Factors Associated with Depression and Anxiety Symptoms Among Medical Students in Bahrain. Acad Psychiatry. Academic Psychiatry; 2017;42:31-40.

22. Azim SR, Baig M. Frequency and perceived causes of depression, anxiety and stress among medical students of a private medical institute in Karachi : a mixed method study. J Pak Med Assoc. 2017;69:840-5.

23. Fawzy M, Hamed SA. Prevalence of psychological stress, depression and anxiety among medical students in Egypt. Psychiatry Res. Elsevier Ireland Ltd; 2017;255:186-94.

24. Fata Nahas ARM, Elkalmi RM, Al-Shami AM ET. Prevalence of Depression Among Health Sciences Students: Findings From a Public University in Malaysia. J Pharm Bioallied Sci. 2019;11:170-5.

25. Goebert D, Thompson D, Takeshita J, Beach C, Bryson P, Ephgrave K, et al. Depressive Symptoms in Medical Students and Residents: A Multischool Study. Acad Med. 2009;84:236-41.

26. Vankar JR, Prabhakaran A, Sharma H. Depression and Stigma in Medical Students at a Private Medical College. Indian J Psychol Med I. 2014;36:246-54.

27. Yoon S, Lee Y, Han C, Steffens DC, Kim Y. Usefulness of the Patient Health Questionnaire-9 for Korean Medical Students. Acad Psychiatry. 2014;38:661-7. 
28. Roh M, Jeon HJ, Kim H. The Prevalence and Impact of Depression Among Medical Students: A Nationwide Cross-Sectional Study in South Korea. Acad Med. 2010;85:1384-90.

29. Lin YK, Lin C, Lin BY, Chen D. Medical students' resilience: a protective role on stress and quality of life in clerkship. BMC Med Educ. BMC Medical Education; 2019;19:473.

30. Ibrahim N, Kharboush DA-, El-khatib L, Al A, Asali D. Prevalence and Predictors of Anxiety and Depression among Female Medical Students in King Abdulaziz University, Jeddah, Saudi Arabia. Iran J Publ Heal. 2013;42:726-36.

31. Shankar N, Singh S, Gautam S, Dhaliwal U. Motivation and preparedness of first semester medical students for a career in medicine. Indian J Physiol Pharmacol. India; 2013;57:432-8.

32. Sidana S, Kishore J, Ghosh V, Gulati D, Jiloha RC, Anand T. Prevalence of depression in students of a medical college in New Delhi : A cross-sectional study. Australas Med J. 2012;5:247-50.

33. Waqas A, Rehman A, Malik A, Muhammad U, Khan S, Mahmood N. Association of Ego Defense Mechanisms with Academic Performance, Anxiety and Depression in Medical Students: A Mixed Methods Study. Cureus. 2015;7:e337.

34. Sousa JMDE, Moreira CA, Telles-correia D. Anxiety, Depression and Academic Performance: A Study Amongst Portuguese Medical Students Versus Non- Medical Students. Acta Med Port. 2018;31:45462.

\section{Tables}

Due to technical limitations, Tables $1 \& 2$ are only available for download from the Supplementary Files section.

\section{Figures}

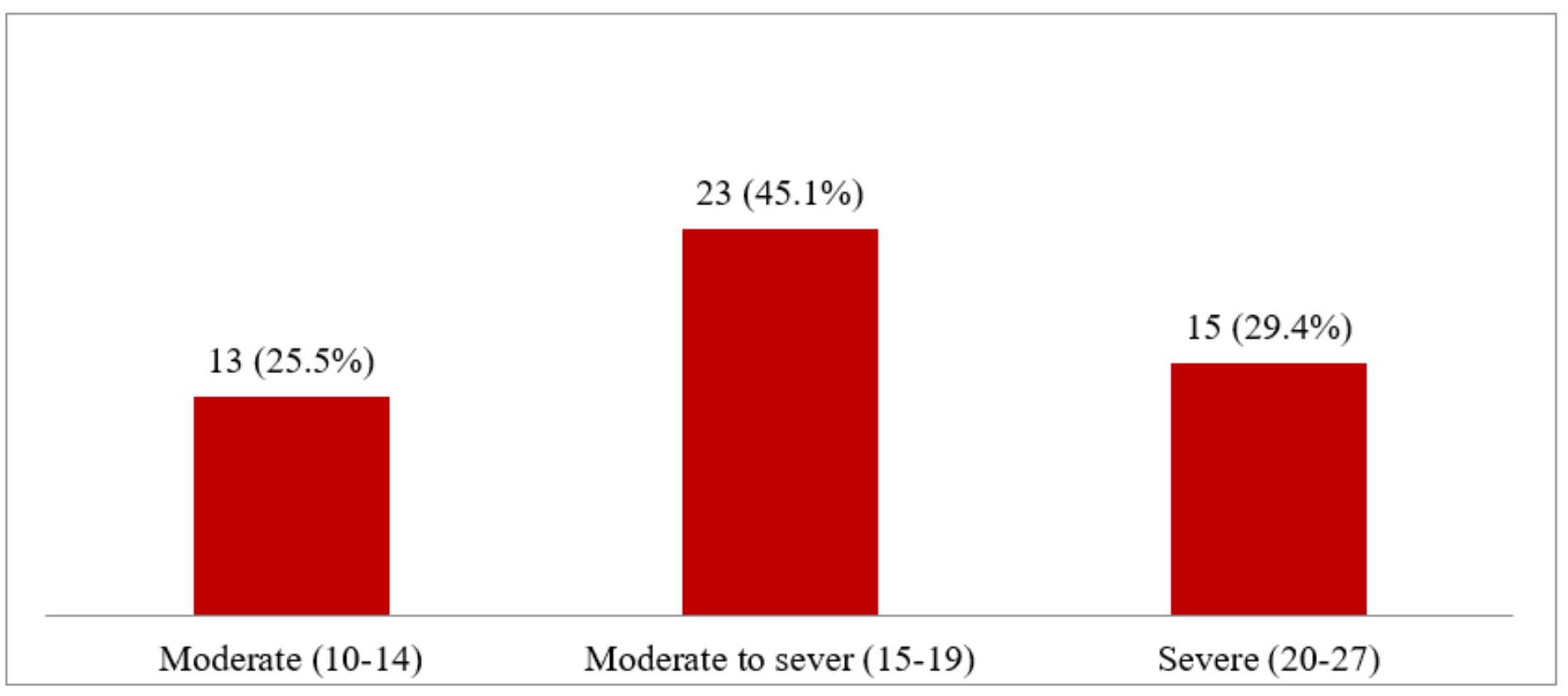


Figure 1

Level of depressive symptoms among medical students $(n=51)$ at the College of Medicine, University of Bisha, Saudi Arabia

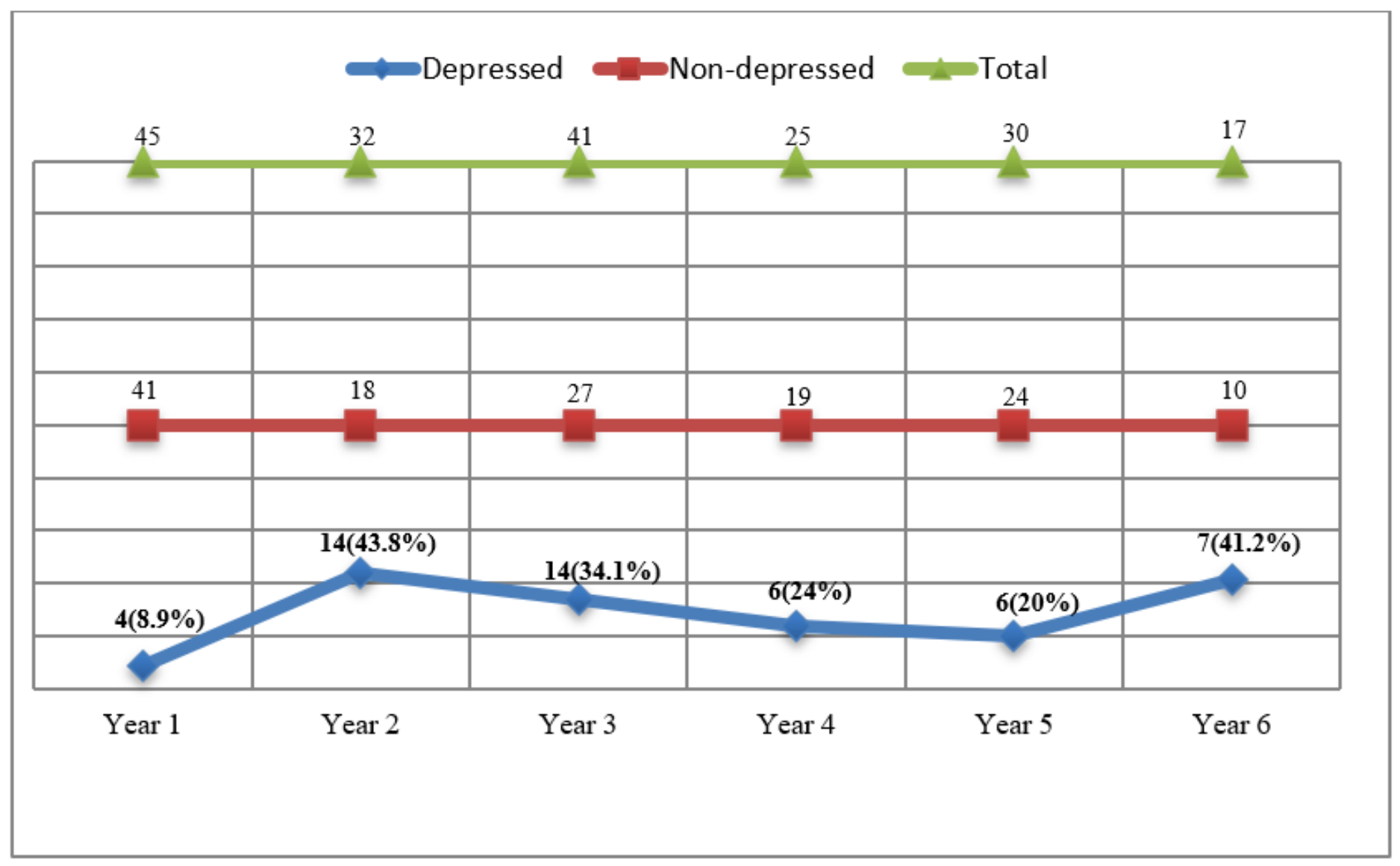

Figure 2

Frequency of depression among medical students by academic year

\section{Supplementary Files}

This is a list of supplementary files associated with this preprint. Click to download.

- Tables.docx 